\title{
Impacts of temperature extremes on European vegetation during the growing season
}

\author{
Lukas Baumbach $^{1,2}$, Jonatan F. Siegmund ${ }^{1,3}$, Magdalena Mittermeier ${ }^{1,4}$, and Reik V. Donner ${ }^{1}$ \\ ${ }^{1}$ Research Domain IV - Transdisciplinary Concepts and Methods, Potsdam Institute for Climate Impact Research, \\ Telegrafenberg A31, 14473 Potsdam, Germany \\ ${ }^{2}$ Faculty of Environment and Natural Resources, Albert Ludwigs University of Freiburg, Tennenbacherstraße 4, \\ 79016 Freiburg im Breisgau, Germany \\ ${ }^{3}$ Institute of Earth and Environmental Science, University of Potsdam, Karl-Liebknecht-Straße 24-25, \\ 14476 Potsdam, Germany \\ ${ }^{4}$ Department of Geography, Ludwig Maximilians University, Geschwister-Scholl-Platz 1, 80539 Munich, Germany \\ Correspondence to: Reik V. Donner (reik.donner@pik-potsdam.de)
}

Received: 15 May 2017 - Discussion started: 19 June 2017

Revised: 28 September 2017 - Accepted: 4 October 2017 - Published: 7 November 2017

\begin{abstract}
Temperature is a key factor controlling plant growth and vitality in the temperate climates of the midlatitudes like in vast parts of the European continent. Beyond the effect of average conditions, the timings and magnitudes of temperature extremes play a particularly crucial role, which needs to be better understood in the context of projected future rises in the frequency and/or intensity of such events. In this work, we employ event coincidence analysis (ECA) to quantify the likelihood of simultaneous occurrences of extremes in daytime land surface temperature anomalies (LSTAD) and the normalized difference vegetation index (NDVI). We perform this analysis for entire Europe based upon remote sensing data, differentiating between three periods corresponding to different stages of plant development during the growing season. In addition, we analyze the typical elevation and land cover type of the regions showing significantly large event coincidences rates to identify the most severely affected vegetation types. Our results reveal distinct spatio-temporal impact patterns in terms of extraordinarily large co-occurrence rates between several combinations of temperature and NDVI extremes. Croplands are among the most frequently affected land cover types, while elevation is found to have only a minor effect on the spatial distribution of corresponding extreme weather impacts. These findings provide important insights into the vulnerability of European terrestrial ecosystems to extreme temperature events and demonstrate how event-based statistics like
\end{abstract}

ECA can provide a valuable perspective on environmental nexuses.

\section{Introduction}

At a global scale, the year 2016 was the warmest year on record, presenting the third consecutive annual record among more than 100 years of observational data (NOAA National Centers for Environmental Information, 2017). For Europe, it was still the third warmest year after 2014 and 2015. In the context of ongoing anthropogenic greenhouse gas emissions, these general tendencies are likely to continue, resulting in an increasing trend of extreme temperature events (Beniston et al., 2007; Coumou et al., 2013). Particularly, hot days and heat waves have been observed to increase in intensity and frequency in the course of the last few decades - prominent examples include the European summer heat waves of 2003, 2006 and 2010 (De Bono et al., 2004; Rebetez et al., 2009; Barriopedro et al., 2011). Additionally, late spring frost events may pose a threat to plant development due to continuously earlier bud burst of plants in spring (Way, 2011).

Both positive and negative temperature extremes can adversely affect a plant's development and vitality. On the one hand, heat stress leads to changes in plant metabolism and the integrity of cells, causing phenomena such as the inhibition of photosystem II, thermal denaturation of proteins 
or the formation of reactive oxygen species (Hasanuzzaman et al., 2013). On the other hand, low temperatures and frosts slow down biochemical processes within the plant cells and may result in the direct damaging or necrosis of new shoots or plant roots as well as indirect damages due to the lack of water access in the frozen soil (frost drought) (Beck et al., 2004). The susceptibility of vegetation to these threats may vary, e.g., depending on the seasonal stage of development (phenophase) and vegetation type (see Sect. 3). Foremost, cultivated plants/croplands show high vulnerabilities to extreme temperatures as their optimal climatic niche is relatively narrow (Larcher, 1994). Thus, temperature as a single variable can already have severe impacts and even be of predominant importance for future agricultural production in Europe (Semenov and Shewry, 2011; Deryng et al., 2014). A basic problem related to analyzing such impacts lies in the definition of temperature extremes. One way to identify extraordinary temperatures is to investigate anomalies of longterm average temperatures during specific time intervals. In this work, we focus our attention on land surface temperature anomalies during daytime (LSTAD), which represent a suitable observable, since they integrate temperature information over the daily active time (photo-period) of most plants. However, we emphasize that nighttime temperatures can also have considerable effects on plants in terms of heat stress by stimulating carbon loss by respiration.

At the prospect of increasing frequencies and/or intensities of extreme temperature events in Europe (Coumou and Rahmstorf, 2012; Tank and Konnen, 2003; Luterbacher et al., 2004; IPCC, 2013; Barriopedro et al., 2011; Petoukhov et al., 2013; Seneviratne et al., 2012), plant communities will in general face ever more challenges to resist the stress imposed on them. A widely used measure for identifying plant stress at regional scales based on remote sensing observations is the normalized difference vegetation index (NDVI). While other more recently developed indices for vegetation characteristics (such as the enhanced vegetation index or the net primary productivity) have been shown to yield advantages over the NDVI in terms of stress detection in plants, the NDVI is still in frequent use. Despite its lower sensitivity to changes of the vegetation cover, the NDVI is a conservative, robust measurement tool (Pettorelli, 2013) and has been comprehensively studied regarding its relationship with temperature variability (see, e.g., Schultz and Halpert, 1993, 1995; Kawabata et al., 2001; Karnieli et al., 2010; Kim et al., 2010). The global data availability for a relatively long period of observations has made NDVI easily applicable to remote sensing studies without the need for exhaustive preprocessing. Because of this, we focus in this work on the analysis of NDVI characteristics while outlining refined studies using more sophisticated indices as a subject of future research.

Up to now, research on climatic drivers of NDVI variations has often concentrated on a global scale (e.g., the aforementioned Schultz and Halpert, 1993, 1995; Kawabata et al., 2001; Karnieli et al., 2010; Kim et al., 2010), whereas re- gional studies like Wang et al. (2003) and Hao et al. (2012) are still rare. In the face of global warming, however, especially inter-regional climate disparities are projected to increase (Ciscar et al., 2011; Iglesias et al., 2012), thus emphasizing the need for regional research.

Moreover, most previous studies on the environmental impacts of changing temperatures have focused on the detection of linear relationships between different variables by means of correlation and regression analysis (see, e.g., Schultz and Halpert, 1995; Los et al., 2001; Ichii et al., 2002; Wang et al., 2003; Stöckli and Vidale, 2004; Hao et al., 2012). Linear correlation analysis is a widely applicable tool allowing us to discover linear statistical relationships between environmental variables. However, corresponding changes associated with global warming cannot a priori be assumed to be of linear nature, but may, for example, only occur when a certain threshold is exceeded (see, e.g., Burkett et al., 2005; Rockström et al., 2009). Liu et al. (2013) took this idea a step further by investigating the sensitivity of vegetation to climate extremes by conducting a pixel-wise regression between extremes in vegetation dynamics subject to a Box-Cox data transformation and extremes of precipitation, Palmer drought severity index and temperature.

While the aforementioned approach explored anomalies in the data distribution and took into account a broad ensemble of drought-related indicators, in this work, we specifically focus on analyzing the impacts of extraordinary warm or cold temperature events by utilizing the novel and straightforward method of event coincidence analysis (ECA; Donges et al., 2016). This method differs from linear correlation analysis in that it does not assess the dependence between two variables as a whole, but focuses on simultaneous occurrences of specific events. The theoretical differences between correlation analysis and ECA, as well as the differences in the interpretations of the outcomes of both methods, have been comprehensively discussed in previous papers (Donges et al., 2016; Siegmund et al., 2016a, b, 2017). In summary, correlation analysis reveals the general common behavior (covariance) between two time series, while ECA addresses the commonality in the timing of occurrences of values in a specific part of the empirical distributions (in our case, the tails) of the variables of interest.

Drawing upon the previous considerations, this study aims to identify regions of Europe with a vegetation cover that is particularly sensitive to temperature extremes. For this purpose, we utilize the land surface temperature anomalies during daytime (LSTAD) as a temperature variable and the NDVI as a proxy for the vegetation condition. By studying the behavior during three distinct periods of the year individually, we will distinguish between different types of temperature-vegetation relations during different parts of the growing season. For each of these periods, we additionally study the distributions of statistically significant event coincidence rates among different classes of land cover and ele- 
vation to unveil which types of terrestrial ecosystems may be affected the most by extremal temperature conditions.

The remainder of this paper is organized as follows. The data used in this study and statistical analysis methods employed are introduced in Sects. 2 and 3, respectively. Our main results are described in Sect. 4, followed by a discussion in Sect. 5. The paper concludes with a summary of our main findings.

\section{Data}

The analyses of this study focus on the region from 33 to $73^{\circ} \mathrm{N}$ and $25^{\circ} \mathrm{W}$ to $55^{\circ} \mathrm{E}$, encompassing the entire European continent plus some of the surrounding regions of northern Africa and the Levant. For our calculations, the following data sources are used:

- LSTAD and NDVI satellite images from the Moderate Resolution Imaging Spectroradiometer (MODIS) between 2000 and 2015 are retrieved from the NASA Near Earth Observations Program archive (available at http://neo.sci.gsfc.nasa.gov) at a spatial resolution of $0.1^{\circ}$. For both variables, the highest temporal resolution available is chosen - i.e., 16-day intervals for NDVI (NASA, 2017b) and 8-day intervals for LSTAD (NASA, 2017a).

- Land cover data are obtained from the NASA NEO archive (NASA, 2017c) at the same spatial resolution of $0.1^{\circ}$. Here, the data of the most recent available year (2011) are used.

- For topographic information, the ETOPO1 Global Relief data set (Amante and Eakins, 2009) is downloaded at a 1 arcmin resolution and resampled to a resolution of $0.1^{\circ}$ by means of spatial averaging.

\section{Methods}

Since we aim to study statistical relationships between the occurrences of extreme events in LSTAD and NDVI (see Sect. 2) for different periods (Sect. 3.1), we first identify these events for each grid cell (in the following referred to as a pixel) individually (Sect. 3.2). We then apply ECA (Sect. 3.3) to the resulting pairs of event sequences for each pixel. The resulting event coincidence rates are then presented on maps of the study area and additionally evaluated regarding their dependence on land cover type and elevation (Sect. 3.4).

\subsection{Analyzed time periods}

We subdivide our analysis into different periods of time during the growing season. This distinction reflects the hypothesis that a plant's vulnerability to temperature extremes strongly depends on its respective stage of development - i.e., its phenophase (Hatfield and Prueger, 2015). Strictly speaking, it would be beneficial to define the relevant phenophase for each pixel within our study area separately (reflecting different climatic conditions and predominant plant types). However, an investigation of this kind would also require the consideration of a large number of additional effects influencing local vegetation (e.g., continentality, micro-climate, interannual phenophase shifts). Since such an analysis would extend beyond the limits of the present study, we take here an average continental-scale perspective to identify regional instead of local impact patterns. Therefore, we base the subdivision of the analysis on central European average phenology (Ellenberg and Leuschner, 2010). The chosen time intervals of March-April, May-June and July-September here correspond to the prevernal, vernal and serotinal phases of central European vegetation. Specifically, the prevernal phase (early spring) represents the first development of shoots and usually covers the time from March to April in central Europe. In the subsequent vernal phase (spring) lasting from May to mid-June, leaves are fully proliferated. The time between July and September can be divided into the aestival (mid-June to mid-July) and serotinal phase (mid-July to September), the latter of which is characterized by the aging of the foliage (Tansley, 1993). As most plants are already fully developed at the start of the aestival phase, we extend here our working definition of the serotinal phase to cover all of July and expand the vernal phase up to the end of June for the sake of simplicity. This results in three different parts of the growing season investigated in this study: March-April (prevernal phase), May-June (vernal phase) and July-September serotinal phase). We emphasize that this classification is only accurate for central Europe, while the phenophases differ in onset and length in other parts of Europe. The subdivision should thus be understood as a starting point for differentiating between impacts during different seasons but does not allow for a systematic intercomparison between vegetation responses to climate stress among different parts of Europe from the plant physiological perspective.

\subsection{Event definitions}

\subsubsection{NDVI}

The temporal resolution of the available NDVI data already determines a minimum time interval of 16 days that an event would represent. We emphasize that the notion of the term "event" as used in the present work should therefore be understood in a statistical, not a synoptic-scale meteorological sense. While the investigation of shorter intervals may appear desirable, one has to note that the reaction time of the NDVI to temperature changes can strongly depend on the type of ecosystem and its resilience or vulnerability in 
the presence of perturbations (Gonzalez et al., 2010). In this context, NDVI responses to climate extremes can either be instantaneous or show time lags of even up to 1 month (Tan et al., 2015). Bearing this fact in mind, in addition to the practical necessity of this strategy, defining extreme NDVI events upon a temporal resolution of 16 days appears a reasonable trade-off to account for both instantaneous and delayed responses at least to a certain degree.

To distinguish between the presence or absence of an extreme event at the given temporal aggregation level, we chose the 10th and 90th percentiles of the available data for each pixel and each time period as upper and lower thresholds for defining extremely low and extremely high NDVI values. This approach already accounts for the diverse nature of the very large study area because, e.g., an "extremely low NDVI value" is always defined in relation to the typical distribution of local NDVI values at a given pixel during the time period being analyzed. For example, a "low NDVI event" in a semiarid savanna region might have a very different practical meaning than a "low NDVI event" in a humid temperate forest. Yet, both events are unusual with respect to the local conditions and the current phenophase. By defining the events separately for each time period, the seasonal development cycle is taken into account automatically, and no further preprocessing like (practically rather challenging) deseasonalization of the data prior to further analysis is necessary.

It should also be noted that changes in the NDVI may be attributed to different underlying mechanisms, which may not be distinguished safely through analysis of remotesensing-based observations. While in this work, we specifically analyze the co-occurrence of very atypical NDVI values with episodes of extraordinary temperature anomalies, other factors including human activities like harvests or land use changes may also lead to NDVI anomalies, which need to be considered for an appropriate interpretation of the results.

Lastly, we note that for regions with a dense vegetation cover and a correspondingly high leaf area index during the vegetation period, NDVI is known to follow a saturation curve and to be insensitive to changes in leaf area or biomass at high levels (see studies by, e.g., Huete et al., 1997; Aparicio et al., 2000). However, this issue mostly applies for high biomass situations like those present in tropical rain forests and is unlikely to affect the results for our study region to a critical extent.

\subsubsection{Temperature}

The definition of the extreme temperature events is performed in the same way as for the NDVI, with the only difference that the 8-day LSTAD information is averaged to 16-day data first. The temperature values thus obtained do not exhibit any temporal mismatch with respect to the NDVI data. Moreover, as for the NDVI, the pixel-wise approach for different time periods accounts for the spatial and seasonal variability.

\subsubsection{Event combinations}

The discrimination of the 16-day LSTAD and NDVI data into three time periods results in time series of 64 (March-April and May-June) or 96 (July-September) data points for each pixel. Accordingly, for the time intervals March-April and May-June, the 10 and $90 \%$ threshold definitions identify six low (negative) and six high (positive) events per time series, while for July-September, nine low and nine high events are selected. Takeing these different types of events in both time series (NDVI and LSTAD) leaves us with four possible event combinations to be considered for each part of the growing season:

1. both LSTAD and NDVI are greater than their respective empirical $90 \%$ quantiles (in the following referred to as T90-V90),

2. both LSTAD and NDVI are lower than their $10 \%$ quantile (T10-V10),

3. LSTAD lower than its $10 \%$ and NDVI greater than its $90 \%$ quantile (T10-V90), and

4. LSTAD greater than its $90 \%$ and NDVI lower than its $10 \%$ quantile (T90-V10).

In summary, we emphasize that in the present study, the term extreme describes values in the tails of the distributions of both considered types of data set rather than record-like events. The limited time span of available satellite measurements results in these extremes also including potentially still relatively moderate seasonal anomalies. However, in the classical peaks-over-threshold sense, it appears reasonable to consider the identified events as extremes.

\subsection{Event coincidence analysis}

In order to test for the non-random nature of potential cooccurrences between events in two time series, we apply ECA using the R package CoinCalc (Siegmund et al., 2017). ECA computes the empirical fraction of simultaneous events in two series (so-called coincidences), which is referred to as the event coincidence rate (ECR). By definition, this ECR takes values between 0 and 1 , where 0 indicates that the events in both series never occur simultaneously (indicating the absence of a corresponding instantaneous statistical relationship), whereas an ECR of 1 implies that the events in both series always occur simultaneously. We emphasize that similar approaches have also been used recently by other authors in the context of remote-sensing-based analyses of ecosystem responses to climatic drivers (Zscheischler et al., 2015).

We assess the statistical significance of the ECRs thus obtained using a simple analytical significance test against the null hypothesis of two independent Poisson processes with low event rates (Donges et al., 2016), using a significance 
Table 1. Share of each land cover class on the total study area. Pixels classified as "no data" cover $1.23 \%$ of the area.

\begin{tabular}{lr}
\hline IGBP land cover units & Areal share (\%) \\
\hline Croplands & 25.190 \\
Mixed forest & 20.870 \\
Grasslands & 14.245 \\
Cropland/natural vegetation mosaic & 9.318 \\
Woody savannas & 8.279 \\
Open shrublands & 7.022 \\
Evergreen needleleaf forest & 5.913 \\
Barren or sparsely vegetated & 4.118 \\
Deciduous broadleaf forest & 1.362 \\
Permanent wetlands & 0.826 \\
Urban and built-up & 0.819 \\
Permanent snow and ice & 0.504 \\
Savannas & 0.274 \\
Closed shrublands & 0.017 \\
Evergreen broadleaf forest & 0.006 \\
Deciduous needleleaf forest & 0.002 \\
\hline
\end{tabular}

level of $\alpha=0.05$. Thereby, we obtain spatial and temporal patterns of statistically significant event coincidence rates (SCRs). Specifically, we apply ECA for each joint pixel of the NDVI and LSTAD data individually, resulting in one ECR for each pixel and time period.

Note that in this work, we do not further account for possible lagged vegetation responses to temperature extremes due to the coarse temporal resolution of our data, which may result in time windows capturing both instantaneous as well as lagged responses. Methodologically speaking, if an additional time lag were included, one would have to consider the ECA as a directional analysis tool that distinguishes between the so-called precursor rate and trigger rate (Donges et al., 2016). In our setting, however, both rates are always the same by definition.

\subsection{Land cover and topography analyses}

In addition to the spatially explicit (pixel-wise) analysis described above, we are also interested in the role of elevation and land cover type as possible covariates determining the vegetation response to temperature extremes.

For the possible effects of elevation, the altitude values of all pixels were grouped into six classes defined based on the altitudinal zonation of Frey and Lösch (2014) as follows: planar (below $100 \mathrm{~m}$ a.s.1.), colline (100-500 m a.s.1.), submontane (500-1000 m a.s.l.), montane (1000-1600 m a.s.1.), subalpine (1600-2000 m a.s.l.), alpine (2000-3000 m a.s.l.) and nival (above $3000 \mathrm{~m}$ ). Since only very few pixels fell under the definition of the nival zone, these were combined with the alpine class.

The land cover classification followed the International Geosphere-Biosphere Programme (IGBP) land cover classification scheme (Strahler et al., 1999), excluding the class "water bodies". The shares of the individual land cover classes are summarized in descending order in Table 1. As evergreen broadleaf forests and deciduous needleleaf forests make up a negligibly small fraction of the total study area, these two classes have been excluded from the land cover analysis, effectively leaving 14 classes. Furthermore, due to a discrepancy of land-water masks, the land cover image identified some pixels as water area which the NDVI and LSTAD images does not. To account for this data issue, the affected pixels were classified as "no data" and also excluded from the land cover analysis.

\section{Results}

\subsection{March-April}

Figure 1a and $\mathrm{b}$ summarize the results of ECA for the time period March-April. The combination of extremely high temperatures with high NDVI values (T90-V90, green pixels in Fig. 1a) results in SCRs on $14.65 \%$ of the terrestrial part of the study area. In central and southern Europe, we find spatially contiguous regions of SCRs over mountain regions such as the Alps, the Caucasus and the Carpathians. Further important patches of SCRs exist in large parts of the lowlands of northeastern Europe (e.g., the East European Plain and Finnish Lakeland) as well as along the southeastern coast of Norway and the coastal regions of Iceland.

In contrast, SCRs between low-temperature extremes and extremely low NDVI values (T10-V10, red pixels in Fig. 1b) are widely spread on disconnected patches across large parts of continental central Europe, the British Isles and southern Scandinavia. The aforementioned mountain ranges do not appear in this analysis. In total, $13.44 \%$ of the study area shows SCRs between low-temperature and low-NDVI events.

The SCRs between low-temperature extremes and extremely high NDVI values (T10-V90, green pixels in Fig. 1b) are sparsely sprinkled across Europe's south, North Africa and northern Scandinavia, covering only about $2.5 \%$ of the total study area. Given the considered confidence level of our significance test, we would accept a false positive rate of $5 \%$ in our detected pixel-wise SCRs, implying that the observed pixels with SCRs barely carry any practically relevant information. A similar conclusion applies to the combination between high-temperature extremes and extremely low NDVI events (T90-V10, red pixels in Fig. 1a), which also reveals only few pixels with SCRs (3.34\% of the study area), mainly within the Fertile Crescent and across the Mediterranean coast of North Africa.

\subsection{May-June}

Unlike the results for early spring, Fig. 1c only shows a small fraction of SCRs for T90-V90 during May and June (green pixels). As an exception, Scandinavia exhibits a relatively 


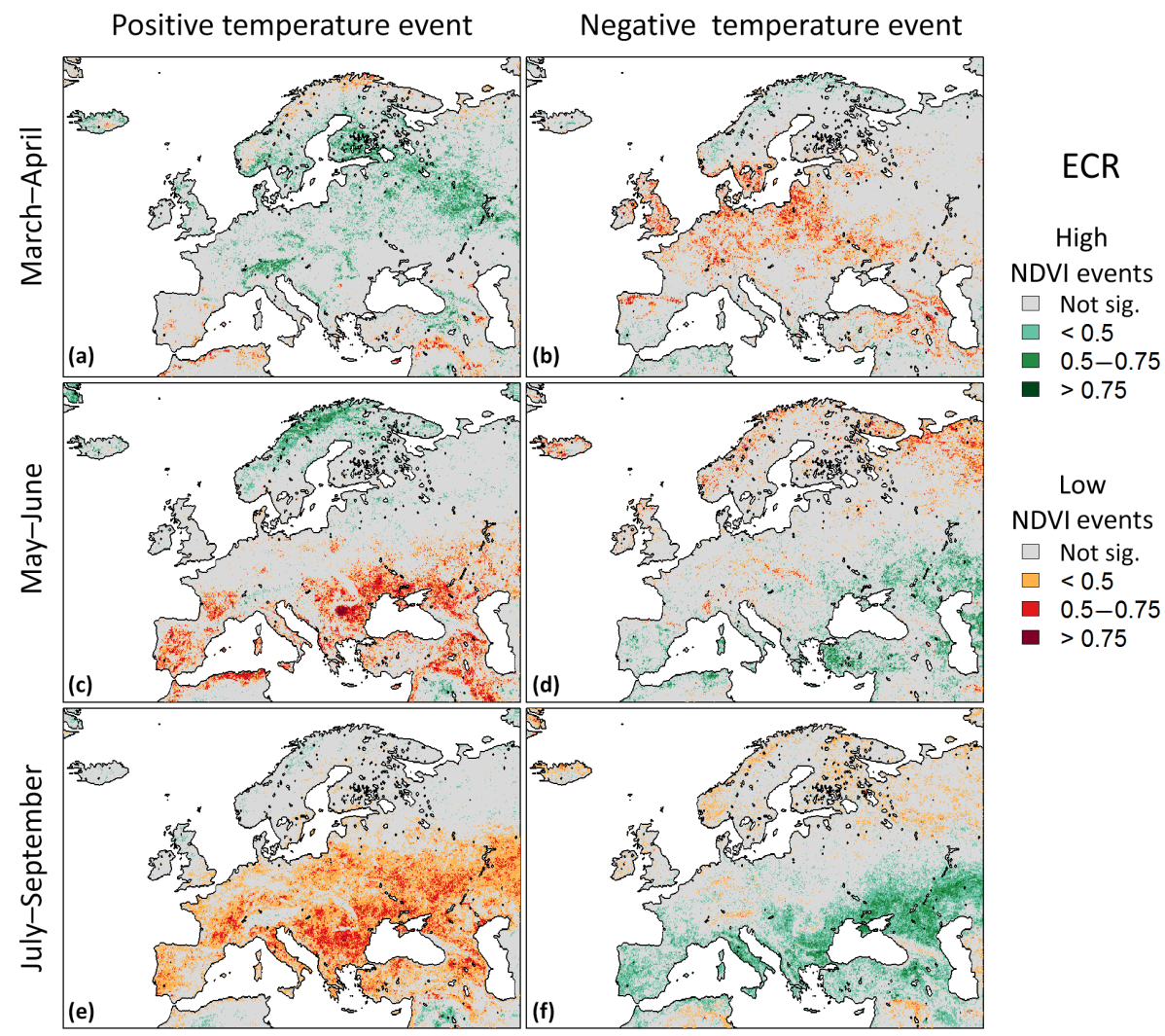

Figure 1. Spatial patterns of significant event coincidence rates (SCRs) between different combinations of low (a, $\mathbf{c}, \mathbf{e})$ and high (b, d, f) temperature and NDVI extremes during the three considered time periods, derived from MODIS satellite measurements from 2000 to 2015 . Red colors show SCRs between temperature-related extremes and extremely low NDVI values, green colors such for extremely large NDVI values. Gray areas indicate pixels with non-significant event coincidence rates.

high density of pixels with SCRs, which contribute most to the $5.52 \%$ of pixels with SCRs within the total study area.

The combination T10-V10 (Fig. 1d, red pixels) also shows only a relatively low density of pixels with SCRs with the exception of northwestern Russia along the coastline of the Arctic Ocean ( $7.80 \%$ of the total study area).

In turn, the analysis of T10-V90 during May and June (Fig. 1d, green pixels) reveals SCRs in $9.37 \%$ of the study area. Here, the most important agglomerations can be found in eastern Europe around the Black Sea, Caspian Sea and Anatolia (especially in its western part).

The most prominent signature of spatially contiguous areas with SCRs during May-June can be observed in Fig. 1c for the analysis of T90-V10 (red pixels). Here, the SCRs cover $16.58 \%$ of the total area and concentrate in five distinct regions: (i) in a belt-like region around the west, north and east of the Black Sea; (ii) along the Fertile Crescent, including more northern regions around Azerbaijan; (iii) in a large patch over southern France north of the Pyrenees; (iv) in more or less the entire Iberian Peninsula (excluding the Pyrenees and the Atlantic coast); and (v) along the Mediterranean coast of the Maghreb regions. We particularly note that over large parts of Wallachia (the flatlands between the Carpathians and the Balkans), the analysis for T90-V10 reveals ECRs of 1 .

\subsection{July-September}

The third considered time period only exhibits a negligible number of SCRs over Europe for T90-V90 (Fig. 1e, green pixels). Only a small agglomeration of SCRs can be found in northwest Mesopotamia, accounting for just $1.79 \%$ of the total study area.

For T10-V10, a broad geographic distribution of SCRs is present (Fig. 1f, red pixels). Notably, these results resemble the observations for the same combination in May-June to a certain degree: the SCRs are loosely spread in the Scandes and northwest Russia (6.88\% of the total study area).

The co-occurrence patterns of T10-V90 (Fig. 1f, green pixels) are concentrated in a latitudinal belt (approximately between 40 and $45^{\circ} \mathrm{N}$ ) from the Caspian Depression via the Kuma-Manych Depression (north of the Caucasus Mountains), the Balkans, almost entire Italy to parts of the Iberian Peninsula. The Caucasus Mountains and the Alps appear to 


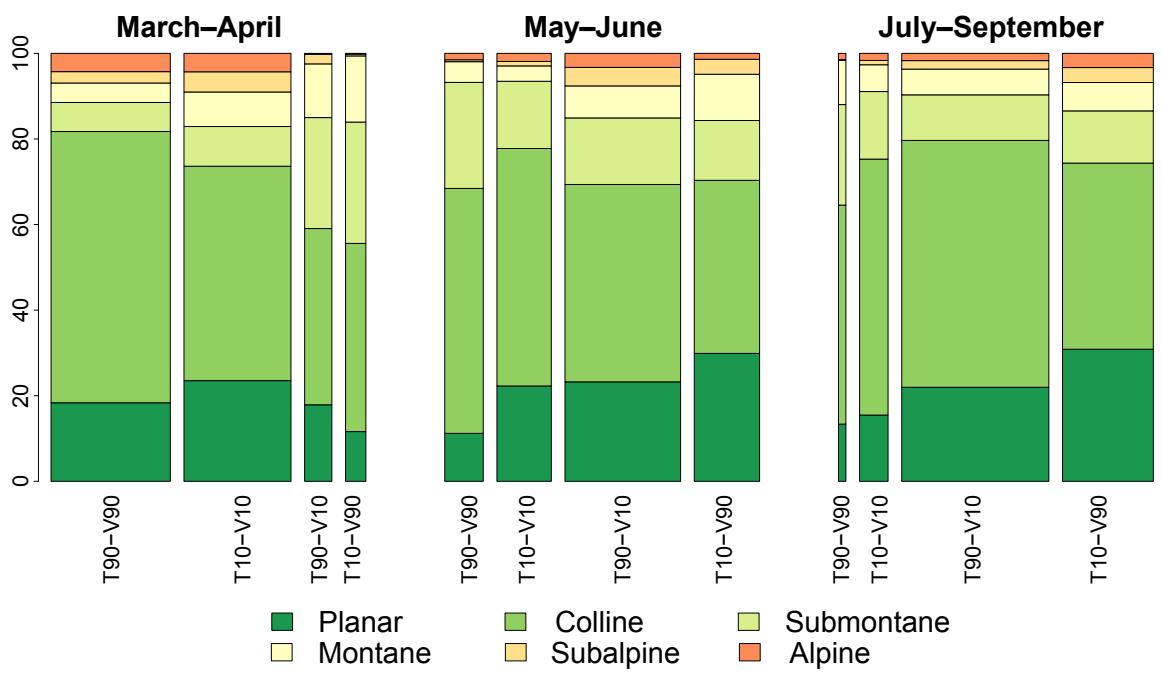

Figure 2. Distribution of pixels with SCRs among the seven altitudinal classes (in percent) for all four event combinations in the three time periods. The width of the columns represents the fraction of pixels with SCRs of the specific event combination within the total study area.

be distinctively excluded from this pattern. In total, $21.93 \%$ of the study area shows SCRs for T10-V90.

Finally, the combination T90-V10 (Fig. 1e, red pixels) exhibits a widespread SCR pattern, which covers almost all of western, central and eastern Europe. Especially high ECRs are found between the Adriatic and the Black Sea, while remarkable areas without SCRs include major mountain ranges like the Alps, the Pyrenees, the northern Carpathians and the Caucasus Mountains. For this combination, $35.52 \%$ of the total study area is covered by SCRs.

\subsection{Topographical effects}

Figure 2 illustrates the distribution of pixels exhibiting SCRs (for every combination of events and all three time periods) among the six elevation classes. The width of the displayed bars indicates the fraction of pixels with SCRs among the total study area and therefore (to a certain degree) underlines the relevance of this event combination during the respective time period. The SCRs for the two event combinations T90V90 and T10-V10 during March-April (Fig. 2, left panel) mostly occur on elevation levels of the planar and colline zone, while T10-V10 has a slightly higher tendency towards higher elevations than T90-V90. The alpine zone also exhibits a notable number of pixels with SCRs as compared to the other two event combinations. When comparing this to Fig. 1a, b, the pixels of the alpine zone seem to mainly result from event coincidences in the European Alps for T90-V90 and the Pyrenees and Caucasus Mountains for T10-V10. The few significant pixels of the other two event combinations (T90-V10 and T10-V90) are evenly distributed throughout all elevation classes but the alpine zone.

For the time period May-June (Fig. 2, central panel), the largest differences between the event combinations can be found in the planar zone, where T10-V90 exhibits SCRs at a more than twice as large fraction of pixels as compared to T90-V90. Notably, the event combination T10-V90 shows a clearly higher contribution at the subalpine and alpine zone than the other event combinations, which presumably mainly results from the SCRs in western Anatolia (see Fig. 1d).

The two event combinations showing the most SCRs during the time July-September (T90-V10 and T10-V90, right panel of Fig. 2) again contain the most pixels in the lowest two elevation zones. Yet, T10-V90 has a distinctively larger fraction of pixels with SCRs in the higher four zones than T90-V10, especially in the alpine zone.

\subsection{Land cover effects}

The results for the analysis of the underlying land cover classes of the SCRs are summarized in Fig. 3. Like for the topographical analyses, the fraction of pixels exhibiting SCRs is plotted in stacked bars, where the width of the bars reflects the share of significant pixels on the entire study area.

Within the time period March-April (Fig. 3, left panel) SCRs of the event combinations T90-V90 and T10-V10 mainly occur on pixels classified as mixed forests and evergreen needleleaf forests as well as the two cropland classes. The fraction of pixels with SCRs on forests is clearly larger for T90-V90 than for T10-V10, which is replaced in T10 V10 by grassland and cropland. The two other event combinations, which exhibit much fewer SCRs in general, are dominated by open shrubland and cropland.

During May-June (Fig. 3, central panel) the SCRs of the event combinations T90-V90 and T10-V10 are relatively evenly distributed among mixed and evergreen needleleaf forests, woody savanna, open shrubland and grassland. In contrast, the SCRs of T90-V10 and T10-V90 almost only 


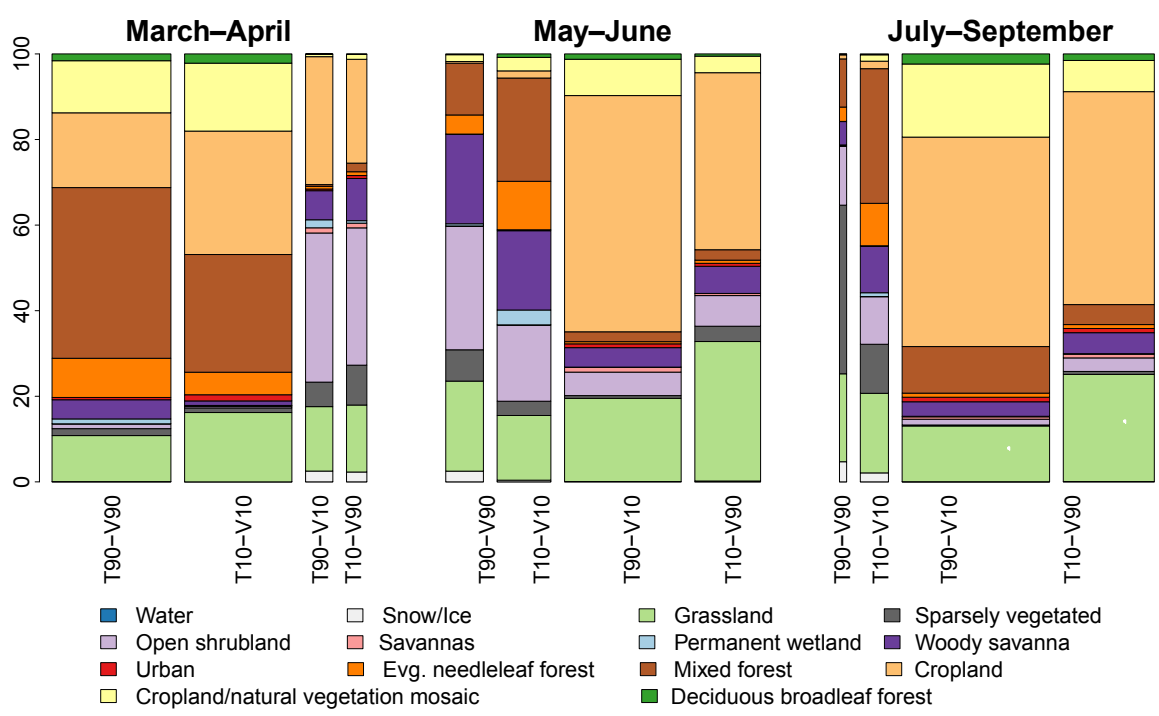

Figure 3. Same as in Fig. 2, for the 14 land cover classes.

occur on pixels classified as cropland or grassland, where for T10-V90 grassland plays a much more important role than for T90-V10.

Finally, for the time from July to September (Fig. 3, right panel) the dominant event combinations T90-V10 and T10V90 show a picture similar as for May-June, yet with a distinctively higher fraction of SCRs on mixed forests.

\section{Discussion}

\subsection{March-April}

The most important finding for the time period March-April is that the strongest impacts of temperature extremes appeared for the two event combinations V90-T90 and V10T10 (joint positive and negative extreme values, respectively). This suggests a generally positive statistical relationship between LSTAD and NDVI in early spring. Although temperature is widely known to be among the most crucial factors for most plants' physiological regulation during this period of the year (see, e.g., Summerfield and Roberts, 1988; Srikanth and Schmid, 2011), it is surprising that the SCR signatures in Fig. 1a, b only cover comparatively small parts of the study area. In more detail, most SCRs for V90-T90 occur in regions which normally exhibit low temperatures (as compared to the rest of the study area) at that time of the year: northern Europe and high mountain ranges such as the Alps and the Caucasus Mountains. The topographical analysis (Fig. 2) confirms the increased relevance of higherelevation classes. Similar observations have been made by Cannone et al. (2007), who found fast growth responses of alpine vegetation to increasing temperatures, since the length of the snow cover season decreased. At the same time, earlier bud burst at these altitudes increases the vulnerability of the vegetation to freezing events after a short window of warm conditions (Wheeler et al., 2014).

The land cover analysis suggests that especially croplands, mixed forests, evergreen needleleaf forests and grasslands benefit from extraordinary warm conditions during early spring. On the other hand, also negative effects of cold periods are mainly visible on croplands in the East European Plain (chiefly wheat and corn fields) and central Europe (fruit trees, field crops). Being adapted to a narrow range of climatic conditions, most of these croplands have been reported to be vulnerable to late spring frost events and might be at even larger risk when the growing season extends earlier into the year (Chmielewski et al., 2004; Lavalle et al., 2009; Trnka et al., 2014). For example, in 2007 the wheat belt of the North European Plain (stretching from northern France to the Baltic) experienced a spring backlash after an unusually warm winter followed by a dry and cold spring (USDA, 2007). As a result, heat-advanced crops were damaged throughout northern central Europe, which is also visible in the results of Fig. $1 b$.

Although the patterns for the other two event combinations are not as pronounced as for the aforementioned two, three distinct regions showed very specific behaviors: the Scandes, the Atlas Mountains and Mesopotamia (see Fig. 1a, b). The dominant land cover class in these three regions is open shrubland (see Fig. 3), which the IGBP classifies as "lands with woody vegetation less than $2 \mathrm{~m}$ tall and with shrub canopy cover between 10 and $60 \%$. The shrub foliage can be either evergreen or deciduous" (Strahler et al., 1999, p. 17). This sparse canopy cover leaves the soil prone to a loss of moisture during high temperature events, which may in the course damage non-perennial grass seedlings that heavily de- 
pend on moist conditions in the top soil layer (Harrington, 1991). While this phenomenon can already be observed in spring in these regions, it appears throughout the season and seems to reach its peak in the time period May-June.

Already at this point, it is very important to note that the SCR patterns of T90-V90 and T10-V10 (as well as those of T10-V90 and T90-V10) do not match in many cases. This implies, that in many parts of Europe, a positive or negative relationship between temperature and NDVI is only valid for one tail of the empirical distribution, which presents a finding that could not be deduced based upon classical linear correlation analyses (e.g., Schultz and Halpert, 1995; Los et al., 2001; Ichii et al., 2002; Wang et al., 2003; Stöckli and Vidale, 2004; Hao et al., 2012).

\subsection{May-June}

For the time between May and June, SCRs for the event combination T90-V90 exhibit a distinct pattern in the northern Scandes. When comparing these results to the same combination during March-April, the observed phenomenon appears to have shifted northwards, presumably due to the later onset of spring in these latitudes. On the other hand, SCRs of T10-V10 are particularly frequent in the northeastern parts of the study area. As mentioned before, this observation may be due to damages induced by cold spells during bud burst or, more likely, late snowfall events that hide the sparse tundric vegetation cover (Dierßen, 1996) from being seen by MODIS.

The largest amount of SCRs appeared for T90-V10. While this heat stress situation is found relevant for vast parts of Europe, croplands and partly grasslands were the most affected land cover types. One reason for this particular sensitivity could be the following. As crops are meant to produce a maximum yield, they often demand high standards in nurturing and water availability and are vulnerable to sudden changes (Semenov and Shewry, 2011; Ma et al., 2015). As already discussed in the Introduction, extreme temperatures can cause substantial losses in crop yields (see, e.g., Schaap et al., 2011; Lesk et al., 2011; Moriondo et al., 2010; Wreford and Adger, 2010). For instance, in 2011 France experienced one of the warmest springs on record which resulted in a $12 \%$ decrease in grain harvest (Coumou and Rahmstorf, 2012; NOAA, 2012). Similarly, based on our results (Fig. 1c), the Wallachia proved to be particularly prone to heat stress. This corroborates observations of Spinoni et al. (2015), who identified almost annually recurring heat waves, with the most extreme cases occurring in 2003 and 2007. However, other lowlands at similar latitudes like the Padan Plain in northern Italy did not exhibit such a behavior. For most parts, we suggest a different water supply situation of these areas (e.g., influenced by continentality, size of the watershed and irrigation) to lead to this finding, while also differing water demands of the vegetation due to different dominating crop types may play a role.
Regarding the repeated appearance of grasslands among the most affected land cover classes for the combination T90-V10, we note that a rapid loss of soil moisture during high temperature events is expected to result in negative NDVI events (Teuling et al., 2010).

\subsection{July-September}

The combination T90-V10 resulted in the highest fraction of SCRs for the time July-September. This result suggests that extremely high temperatures pose a severe threat to the vegetation particularly during this time of the year. Notably, three of the most severe heat waves on record (in the summers of 2003, 2006 and 2010) occurred during our study period (2000-2015) and most likely constitute a main part of the selected upper $10 \%$ of temperature values. Previous studies from these summers confirm largely adverse effects on vegetation throughout Europe, with regionally higher intensities along the Mediterranean coast (De Bono et al., 2004; Ciais et al., 2005; Fischer and Schär, 2010).

While heat waves themselves already pose a considerable challenge to plants, the meteorological conditions preceding these events also need to be considered as they may exacerbate the impacts of heat on vegetation. The 2003 heat wave provides a good example, as it was preceded by unusually dry conditions between February and August (Fischer et al., 2007), which left the vegetation at severe drought stress even before the actual extreme event. Hence, the high share of pixels with SCRs may also result from vegetation, which had already been stressed in previous months and was thus more vulnerable to repeated temperature extremes.

Interestingly, like in May-June, croplands and grasslands were among the most affected land cover types. These results match well with modeled future crop production (Deryng et al., 2014; Teixeira et al., 2013), which also sees southeastern and eastern Europe at a particularly high risk of crop failure due to extreme temperature events in late spring and summer. Still, it needs to be noted that during this time of the year parts of the extremely low NDVI events may also be the result of harvesting activities (Wardlow et al., 2007). For example, in Ukraine winter wheat harvest usually takes place between the end of June and mid-August (USDA, 2016), which would be compatible with the low NDVI values present in this region during the time periods May-June and July-September.

At the same time, SCRs of T10-V90 were found in large areas around the Black and Mediterranean seas. This could be interpreted as a "pause for breath" for crop species that are under continuous stress during that time period of the year. In contrast, the high fraction of grassland pixels among all SCRs of this event combination contradicts this idea, since the composition of grass species can be assumed not to be anthropogenically influenced and thus to be well adapted to the local climate. Another explanation could be that the cold temperature events during this time period also coincide with 
periods of high precipitation, and that the latter (or a combination of both factors) is actually causing the increase in NDVI. This hypothesis shall be further tested in future work.

On a final note, it should be pointed out that the analysis of altitudinal zones yielded no clearly interpretable result. The distribution of SCRs among the different classes more or less represented their parent distributions over the whole study area. This outcome may largely be owing to the fact, that the altitudinal classes were defined uniformly across Europe. That said, especially when looking at the largest European mountain ranges in isolation, the Alps, Carpathians, Pyrenees and Caucasus Mountains indeed showed unique response patterns, which highlights their exceptional position among the European landscape.

\section{Conclusions}

In the context of projected increasing frequencies of temperature extremes in Europe (Coumou and Rahmstorf, 2012; Tank and Konnen, 2003; Luterbacher et al., 2004; IPCC, 2013; Barriopedro et al., 2011; Petoukhov et al., 2013; Seneviratne et al., 2012), the present study has delivered a spatially resolved statistical assessment of the impacts of very high and very low temperature events on European vegetation. By applying event coincidence analysis to highresolution remote sensing data, we have investigated the cooccurrences of extremes in daytime land surface temperature anomalies and the normalized difference vegetation index over a period of 16 years (2000-2015). We have analyzed patterns of significant local event coincidence rates, accounting for the type of land cover and altitudinal zone and assessing which regions might be especially vulnerable to possibly rising frequencies and/or intensities of future extreme temperature events.

Our results revealed that the vulnerability to heat stress (particularly between May and June) is very heterogeneously distributed over Europe. The time between July and September displayed the highest densities of significant event coincidence rates for both high- and low-temperature extremes. This was especially true for southern Europe, which emphasizes the vulnerability of this region to climate extremes also in the context of expected increasing frequencies of future heat waves.

Our analysis of the distribution of significant event coincidence rates among altitudinal classes did not reveal clear results. From a geographical point of view, however, high mountain ranges like the Alps and the Caucasus Mountains formed a visible pattern, which points to unique responses of alpine vegetation as compared to the main patterns across Europe. In contrast, the analysis for the different land cover types revealed that the areas suffering from both lowand high-temperature extremes are mostly anthropogenically shaped landscapes. These ecosystems appear to be particularly sensitive to temperature extremes. Another important finding is that forests hardly exhibited significant event co- incidences rates, which indicates that these vegetation types are more resilient against temperature extremes than others. Mixed forests are an important exception, which clearly benefit from warm temperature events during spring.

Despite the reported achievements, further research on simultaneous occurrences of climatic extremes with vegetation-related extremes is strongly recommended. First, an explicit consideration of moisture-related variables (like precipitation, soil moisture or drought indices) within the framework of event coincidence analysis would surely yield further valuable insights (for example, for differentiating between heat and drought stress, see also Kogan, 2001). Second, an investigation of the vegetation vitality and atmospheric conditions preceding extreme temperature events could clarify the actual impact of a specific event itself on vegetation. Third, further validation of the obtained results based upon different remote sensing data sets (Scheftic et al., 2014) as well as ground-based observations (Loew et al., 2017) appears necessary. In this context, we particularly highlight the necessity to consider additional observables related to vegetation stress in order to study the robustness of our approach and reveal further details on the associated plant physiological processes. For the latter purposes, we also emphasize the possibility of employing previously developed multivariate extensions of the present analysis methodology (Siegmund et al., 2016b). We outline such investigations as a subject of future work.

Code and data availability. All calculations in this work have been based upon the open-source R package CoinCalc, which is available at GitHub (Siegmund, 2017).

All data used in this work are publicly available at the sources described in the main text.

Author contributions. JFS designed the analysis. LB, JFS and MM conducted the analysis. LB and JFS prepared the paper. RVD supervised the analysis and revised the manuscript and the interpretation of the obtained results.

Competing interests. The authors declare that they have no conflict of interest.

Acknowledgements. This work has been financially supported by the German Federal Ministry for Education and Research (BMBF) within the framework of the BMBF Young Investigators Group CoSy-CC ${ }^{2}$ : Complex Systems Approaches to Understanding Causes and Consequences of Past, Present and Future Climate Change (grant no. 01LN1306A). Jonatan F. Siegmund acknowledges funding by the Evangelisches Studienwerk Villigst e.V. The authors express their gratitude to Catrin Gellhorn and Chiranjit Mitra for giving valuable feedback on this work. 
Edited by: Akihiko Ito

Reviewed by: Gerald Moser and two anonymous referees

\section{References}

Amante, C. and Eakins, B.: ETOPO1 1 Arc-Minute Global Relief Model: Procedures, Data Sources and Analysis, NOAA Technical Memorandum NESDIS NGDC-24, National Geophysical Data Center, NOAA, available at: https://doi.org/10.7289/ V5C8276M (last access: 2 May 2017), 2009.

Aparicio, N., Villegas, D., Casadesus, J., Araus, J. L., and Royo, C.: Spectral vegetation indices as nondestructive tools for determining durum wheat yield, Agron. J., 92, 83-91, https://doi.org/10.2134/agronj2000.92183x, 2000.

Barriopedro, D., Fischer, E. M., Luterbacher, J., Trigo, R. M., and García-Herrera, R.: The hot summer of 2010: redrawing the temperature record map of Europe, Science, 332, 220-224, https://doi.org/10.1126/science.1201224, 2011.

Beck, E. H., Heim, R., and Hansen, J.: Plant resistance to cold stress: mechanisms and environmental signals triggering frost hardening and dehardening, J. Biosci., 29, 449-459, https://doi.org/10.1007/bf02712118, 2004.

Beniston, M., Stephenson, D. B., Christensen, O. B., Ferro, C. A., Frei, C., Goyette, S., Halsnaes, K., Holt, T., Jylhä, K., Koffi, B., Palutikof, J., Schöll, R., Semmler, T., and Woth, K.: Future extreme events in European climate: an exploration of regional climate model projections, Climatic Change, 81, 71-95, https://doi.org/10.1007/s10584-006-9226-z, 2007.

Burkett, V. R., Wilcox, D. A., Stottlemyer, R., Barrow, W., Fagre, D., Baron, J., Price, J., Nielsen, J. L., Allen, C. D., Peterson, D. L., Ruggerone, G., and Doyle, T.: Nonlinear dynamics in ecosystem response to climatic change: case studies and policy implications, Ecol. Complex., 2, 357-394, https://doi.org/10.1016/j.ecocom.2005.04.010, 2005.

Cannone, N., Sgorbati, S., and Guglielmin, M.: Unexpected impacts of climate change on alpine vegetation, Front. Ecol. Environ., 5, 360-364, https://doi.org/10.1890/15409295(2007)5[360:UIOCCO]2.0.CO;2, 2007.

Chmielewski, F.-M., Müller, A., and Bruns, E.: Climate changes and trends in phenology of fruit trees and field crops in Germany, 1961-2000, Agr. Forest Meteorol., 121, 69-78, https://doi.org/10.1016/s0168-1923(03)00161-8, 2004.

Ciais, P., Reichstein, M., Viovy, N., Granier, A., Ogée, J., Allard, V., Aubinet, M., Buchmann, N., Bernhofer, C., Carrara, A., Chevallier, F., De Noblet, N., Friend, A. D., Friedlingstein, P., Grünwald, T., Heinesch, B., Keronen, P., Knohl, A., Krinner, G., Loustau, D., Manca, G., Matteucci, G., Miglietta, F., Ourcival, J. M., Papale, D., Pilegaard, K., Rambal, S., Seufert, G., Soussana, J. F., Sanz, M. J., Schulze, E. D., Vesala, T., and Valentini, R.: Europe-wide reduction in primary productivity caused by the heat and drought in 2003, Nature, 437, 529-533, https://doi.org/10.1038/nature03972, 2005.

Ciscar, J.-C., Iglesias, A., Feyen, L., Szabó, L., Van Regemorter, D., Amelung, B., Nicholls, R., Watkiss, P., Christensen, O. B., Dankers, R., Garrotek, L., Goodess, C. M., Hunt, A., Moreno, A., Richards, J., and Sori, A.: Physical and economic consequences of climate change in Europe, P. Natl. Acad. Sci. USA, 108, 2678 2683, https://doi.org/10.1073/pnas.1011612108, 2011.
Coumou, D. and Rahmstorf, S.: A decade of weather extremes, Nat. Clim. Change, 2, 491-496, https://doi.org/10.1038/nclimate1452, 2012.

Coumou, D., Robinson, A., and Rahmstorf, S.: Global increase in record-breaking monthly-mean temperatures, Clim. Change, 118, 771-782, https://doi.org/10.1007/s10584-012 0668-1, 2013.

De Bono, A., Peduzzi, P., Kluser, S., and Giuliani, G.: Impacts of summer 2003 heat wave in Europe, Environ. Alert Bulletin, 2, available at: http://www.unisdr.org/files/1145_ewheatwave.en. pdf, 2004.

Deryng, D., Conway, D., Ramankutty, N., Price, J., and Warren, R.: Global crop yield response to extreme heat stress under multiple climate change futures, Environ. Res. Lett., 9, 034011, https://doi.org/10.1088/1748-9326/9/3/034011, 2014.

Dierßen, K.: Vegetation Nordeuropas: 112 Tabellen, Ulmer, Stuttgart, 1996.

Donges, J. F., Schleussner, C.-F., Siegmund, J. F., and Donner, R. V.: Event coincidence analysis for quantifying statistical interrelationships between event time series, Eur. Phys. J.-Spec. Top., 225, 471-487, https://doi.org/10.1140/epjst/e2015-50233y, 2016.

Ellenberg, H. and Leuschner, C.: Vegetation Mitteleuropas mit den Alpen: in ökologischer, dynamischer und historischer Sicht, Vol. 8104, Ulmer, Stuttgart, 2010.

Fischer, E. and Schär, C.: Consistent geographical patterns of changes in high-impact European heatwaves, Nat. Geosci., 3, 398-403, https://doi.org/10.1038/ngeo866, 2010.

Fischer, E. M., Seneviratne, S., Vidale, P., Lüthi, D., and Schär, C.: Soil moisture-atmosphere interactions during the 2003 European summer heat wave, J. Climate, 20, 5081-5099, https://doi.org/10.1175/JCLI4288.1, 2007.

Frey, W. and Lösch, R.: Geobotanik: Pflanze und Vegetation in Raum und Zeit, Springer-Verlag, https://doi.org/10.1007/978-3662-45281-3, 2014

Gonzalez, P., Neilson, R. P., Lenihan, J. M., and Drapek, R. J.: Global patterns in the vulnerability of ecosystems to vegetation shifts due to climate change, Global Ecol. Biogeogr., 19, 755768, https://doi.org/10.1111/j.1466-8238.2010.00558.x, 2010.

Hao, F., Zhang, X., Ouyang, W., Skidmore, A. K., and Toxopeus, A.: Vegetation NDVI linked to temperature and precipitation in the upper catchments of Yellow River, Environ. Model. Assess., 17, 389-398, https://doi.org/10.1007/s10666-011-9297-8, 2012.

Harrington, G.: Effects of Soil Moisture on Shrub Seedling Survival in Semi-Arid Grassland, Ecology, 72, 1138-1149, https://doi.org/10.2307/1940611, 1991.

Hasanuzzaman, M., Nahar, K., Alam, M. M., Roychowdhury, R., and Fujita, M.: Physiological, biochemical, and molecular mechanisms of heat stress tolerance in plants, Int. J. Mol. Sci., 14, 9643-9684, https://doi.org/10.3390/ijms 14059643, 2013.

Hatfield, J. L. and Prueger, J. H.: Temperature extremes: effect on plant growth and development, Weather Climate Extremes, 10, 4-10, https://doi.org/10.1016/j.wace.2015.08.001, 2015.

Huete, A. R., Liu, H., and van Leeuwen, W. J.: The use of vegetation indices in forested regions: issues of linearity and saturation, in: Proceedings of the 1997 IEEE International Conference on Geoscience and Remote Sensing (IGARSS'97): Remote Sensing A Scientific Vision for Sustainable Development, 4, 1966-1968, https://doi.org/10.1109/IGARSS.1997.609169, 1997. 
Ichii, K., Kawabata, A., and Yamaguchi, Y.: Global correlation analysis for NDVI and climatic variables and NDVI trends: 1982-1990, Int. J. Remote Sens., 23, 3873-3878, https://doi.org/10.1080/01431160110119416, 2002.

Iglesias, A., Garrote, L., Quiroga, S., and Moneo, M.: A regional comparison of the effects of climate change on agricultural crops in Europe, Cli. Change, 112, 29-46, https://doi.org/10.1007/s10584-011-0338-8, 2012.

IPCC: Climate Change 2013: The Physical Science Basis, Contribution of Working Group I to the Fifth Assessment Report of the Intergovernmental Panel on Climate Change, Cambridge University Press, Cambridge, UK, New York, NY, USA, https://doi.org/10.1017/CBO9781107415324, 2013.

Karnieli, A., Agam, N., Pinker, R. T., Anderson, M., Imhoff, M. L., Gutman, G. G., Panov, N., and Goldberg, A.: Use of NDVI and land surface temperature for drought assessment: Merits and limitations, J. Climate, 23, 618-633, https://doi.org/10.1175/2009jcli2900.1, 2010.

Kawabata, A., Ichii, K., and Yamaguchi, Y.: Global monitoring of interannual changes in vegetation activities using NDVI and its relationships to temperature and precipitation, Int. J. Remote Sens., 22, 1377-1382, https://doi.org/10.1080/01431160010028490, 2001.

Kim, Y., Glenn, D. M., Park, J., Ngugi, H. K., and Lehman, B. L.: Hyperspectral image analysis for plant stress detection, American Society of Agricultural and Biological Engineers, Pittsburgh, Pennsylvania, 20-23 June 2010, 1009114, https://doi.org/10.13031/2013.29814, 2010.

Kogan, F. N.: Operational space technology for global vegetation assessment, B. Am. Meteorol. Soc., 82, 1949-1964, https://doi.org/10.1175/15200477(2001)082<1949:OSTFGV>2.3.CO;2, 2001.

Larcher, W.: Ökophysiologie der Pflanzen, Ulmer, Stuttgart, 1994.

Lavalle, C., Micale, F., Houston, T. D., Camia, A., Hiederer, R., Lazar, C., Conte, C., Amatulli, G., and Genovese, G.: Climate change in Europe: 3. Impact on agriculture and forestry, A review, Agronomy for sustainable Development, 29, 433-446, https://doi.org/10.1051/agro/2008068, 2009.

Lesk, C., Rowhani, P., and Ramankutty, N.: Influence of extreme weather disasters on global crop production, Nature, 529, 84-87, https://doi.org/10.1038/nature16467, 2011.

Liu, G., Liu, H., and Yin, Y.: Global patterns of NDVI-indicated vegetation extremes and their sensitivity to climate extremes, Environ. Res. Lett., 8, 025009, https://doi.org/10.1088/17489326/8/2/025009, 2013.

Loew, A., Bell, W., Brocca, L., Bulgin, C. E., Burdanowitz, J., Calbet, X., Donner, R. V., Ghent, D., Gruber, A., Kaminski, T., Kinzel, J., Klepp, C., Lambert, J.-C., Schaepman-Strub, G., Schröder, M., and Verhoelst, T.: Validation practices for satellite based earth observation data across communities, Rev. Geophys., 55, 779-817, https://doi.org/10.1002/2017RG000562, 2017.

Los, S. O., Collatz, G. J., Bounoua, L., Sellers, P. J., and Tucker, C. J.: Global interannual variations in sea surface temperature and land surface vegetation, air temperature, and precipitation, J. Climate, 14, 1535-1549, https://doi.org/10.1175/15200442(2001)014<1535:giviss>2.0.co;2, 2001.

Luterbacher, J., Dietrich, D., Xoplaki, E., Grosjean, M., and Wanner, H.: European seasonal and annual temperature variabil- ity, trends, and extremes since 1500, Science, 303, 1409-1503, https://doi.org/10.1126/science.1093877, 2004.

Ma, X., Huete, A., Moran, S., Ponce-Campos, G., and Eamus, D.: Abrupt shifts in phenology and vegetation productivity under climate extremes, J. Geophys. Res.-Biogeo., 120, 2036-2052, https://doi.org/10.1002/2015jg003144, 2015.

Moriondo, M., Bindi, M., Kundzewicz, Z., Szwed, M., Chorynski, A., Matczak, P., Radziejewski, M., McEvoy, D., and Wreford, A.: Impact and adaptation opportunities for European agriculture in response to climatic change and variability, Mitigation and Adaption Strategies on Global Change, 15, 657-679, https://doi.org/10.1007/s11027-010-9219-0, 2010.

NASA: Land Surface Temperature Anomaly [Day] (8 day) Dataset, available at: http://neo.sci.gsfc.nasa.gov/view.php?datasetId= MOD_LSTAD_E, last access: 2 May 2017a.

NASA: Vegetation Index [NDVI] (16 Day - Terra/MODIS) Dataset, available at: http://neo.sci.gsfc.nasa.gov/view.php? datasetId=MOD13A2_M_NDVI, last access: 2 May 2017b.

NASA: Land Cover Classification (1 year) Dataset, available at: http://neo.sci.gsfc.nasa.gov/view.php?datasetId=MCD12C1_ T1\&date=2011-01-01, last access: 2 May 2017c .

NOAA: 2011 Seasonal Temperature Anomalies, available at: https://www.climate.gov/news-features/featured-images/ 2011-seasonal-temperature-anomalies (last access: 21 August 2017), 2012.

NOAA National Centers for Environmental Information: State of the Climate: Global Climate Report for Annual 2016, available at: http://www.ncdc.noaa.gov/sotc/global/201613, last access: 13 May 2017.

Petoukhov, V., Rahmstorf, S., Petri, S., and Schellnhuber, H.-J.: Quasiresonant amplification of planetary waves and recent Northern Hemisphere weather extremes, P. Natl. Acad. Sci. USA, 110, 5336-5341, https://doi.org/10.1073/pnas.1222000110, 2013.

Pettorelli, N.: The Normalized Difference Vegetation Index, Oxford University Press, Oxford, https://doi.org/10.1093/acprof:osobl/9780199693160.001.0001, 2013.

Rebetez, M., Dupont, O., and Giroud, M.: An analysis of the July 2006 heatwave extent in Europe compared to the record year of 2003, Theor. Appl. Climatol., 95, 1-7, https://doi.org/10.1007/s00704-007-0370-9, 2009.

Rockström, J., Steffen, W. L., Noone, K., Persson, A., Chapin III, F. S., Lambin, E., Lenton, T. M., Scheffer, M., Folke, C., Schellnhuber, H. J., Nykvist, B., De Wit, C. A., Hughes, T., van der Leeuw, S., Rodhe, H., Sörlin, S., Snyder, P. K., Costanza, R., Svedin, U., Falkenmark, M., Karlberg, L., Corell, R. W., Fabry, V. J., Hansen, J., Walker, B., Liverman, D., Richardson, K., Crutzen, P., and Foley, J.: Planetary boundaries: exploring the safe operating space for humanity, Ecol. Soc., 14, 32, https://doi.org/10.5751/es-03180-140232, 2009.

Schaap, B., Blom-Zandstra, M., Hermans, C., Meerburg, B., and Verhagen, J.: Impact changes of climatic extremes on arable farming in the north of the Netherlands, Reg. Environ. Change, 11, 731-741, https://doi.org/10.1007/s10113-011-0205-1, 2011.

Scheftic, W., Zeng, X., Broxton, P., and Brunke, M.: Intercomparison of Seven NDVI Products over the United States and Mexico, Remote Sens., 6, 1057-1084, https://doi.org/10.3390/rs6021057, 2014. 
Schultz, P. and Halpert, M.: Global correlation of temperature, NDVI and precipitation, Adv. Space Res., 13, 277-280, https://doi.org/10.1016/0273-1177(93)90559-t, 1993.

Schultz, P. and Halpert, M.: Global analysis of the relationships among a vegetation index, precipitation and land surface temperature, Remote Sens., 16, 2755-2777, https://doi.org/10.1080/01431169508954590, 1995.

Semenov, M. A. and Shewry, P. R.: Modelling predicts that heat stress, not drought, will increase vulnerability of wheat in Europe, Sci. Rep.-UK, 1, 66, https://doi.org/10.1038/srep00066, 2011

Seneviratne, S. I., Nicholls, N., Easterling, D., Goodess, C. M., Kanae, S., Kossin, J., Luo, Y., Marengo, J., McInnes, K., and Rahimi, M.: Changes in climate extremes and their impacts on the natural physical environment, Managing the risks of extreme events and disasters to advance climate change adaptation, Cambridge University Press, 109-230, https://doi.org/10.1017/cbo9781139177245.006, 2012.

Siegmund, J. F.: Open-source R package CoinCalc, available at: https://github.com/JonatanSiegmund/CoinCalc, last access: 3 November 2017.

Siegmund, J. F., Wiedermann, M., Donges, J. F., and Donner, R. V.: Impact of temperature and precipitation extremes on the flowering dates of four German wildlife shrub species, Biogeosciences, 13, 5541-5555, https://doi.org/10.5194/bg-13-55412016, 2016a.

Siegmund, J. F., Sanders, T. G. M., Heinrich, I., van der Maaten, E., Simard, S., Helle, G., and Donner, R. V.: Meteorological Drivers of Extremes in Daily Stem Radius Variations of Beech, Oak, and Pine in Northeastern Germany: An Event Coincidence Analysis, Front. Plant Sci., 7, 733, https://doi.org/10.3389/fpls.2016.00733, 2016b.

Siegmund, J. F., Siegmund, N., and Donner, R. V.: CoinCalc - A new $R$ package for quantifying simultaneities of event series, Comput. Geosci., 98, 64-72, https://doi.org/10.1016/j.cageo.2016.10.004, 2017.

Spinoni, J., Lakatos, M., Szentimrey, T., Bihari, Z., Szalai, S., Vogt, J., and Antofie, T.: Heat and cold waves trends in the Carpathian Region from 1961 to 2010, Int. J. Climatol., 35, 4197-4209, https://doi.org/10.1002/joc.4279, 2015.

Srikanth, A. and Schmid, M.: Regulation of flowering time: all roads lead to Rome, Cell. Mol. Life Sci., 68, 2013-2037, https://doi.org/10.1007/s00018-011-0673-y, 2011.

Stöckli, R. and Vidale, P. L.: European plant phenology and climate as seen in a 20-year AVHRR land-surface parameter dataset, Int. J. Remote Sens., 25, 3303-3330, https://doi.org/10.1080/01431160310001618149, 2004.

Strahler, A., Muchoney, D., Borak, J., Friedl, M., Gopal, S., Lambin, E., and Moody, A.: MODIS Land Cover Product Algorithm Theoretical Basis Document (ATBD) Version 5.0, Tech. rep., Boston University, 1999.

Summerfield, R. J. and Roberts, E. H.: Photo-thermal regulation of flowering in pea, lentil, faba bean and chickpea, Springer the Netherlands, 911-922, https://doi.org/10.1007/978-94-0092764-3_72, 1988.

Tan, Z., Tao, H., Jiang, J., and Zhang, Q.: Influences of Climate Extremes on NDVI (Normalized Difference Vegetation Index) in the Poyang Lake Basin, China, Wetlands, 35, 1033-1042, https://doi.org/10.1007/s13157-015-0692-9, 2015.
Tank, K. and Konnen, G.: Trends in indices of daily temperature and precipitation extremes in Europe, 1946-99, J. Climate, 16, 3665-3680, https://doi.org/10.1175/15200442(2003)016<3665:tiiodt>2.0.co;2, 2003.

Tansley, A. G.: An Introduction to Plant Ecology, Discovery Publishing House, 1993.

Teixeira, E., Fischer, G., van Velthuizen, H., Walter, C., and Ewert, F.: Global hot-spots of heat stress on agricultural crops due to climate change, Agr. Forest Meteorol. 170, 206-215, https://doi.org/10.1016/j.agrformet.2011.09.002, 2013.

Teuling, A. J., Seneviratne, S. I., Stöckli, R., Reichstein, M., Moors, E., Ciais, P., Luyssaert, S., Van Den Hurk, B., Ammann, C., Bernhofer, C., Dellwik, E., Gianelle, D., Gielen, B., Grünwald, T., Klumpp, K., Montagnani, L., Moureaux, C., Sottocornola, M., and Wohlfahrt, G.: Contrasting response of European forest and grassland energy exchange to heatwaves, Nat. Geosci., 3, 722727, https://doi.org/10.1038/ngeo950, 2010.

Trnka, M., Rötter, R. P., Ruiz-Ramos, M., Kersebaum, K. C., Olesen, J. E., Žalud, Z., and Semenov, M. A.: Adverse weather conditions for European wheat production will become more frequent with climate change, Nat. Clim. Change, 4, 637-643, https://doi.org/10.1038/nclimate2242, 2014.

USDA: Spring Dryness and Freeze Lowers Europe's 2007/08 Winter Crop Prospects, availabe at: https://www.pecad.fas.usda.gov/ highlights/2007/05/EU_21May07/ (last access: 22 August 2017), 2007.

USDA: Ukraine: 2016/17 Crop Production Forecasts, availabe at: http://pecad.fas.usda.gov/highlights/2016/05/ukraine_ 16may2016/, last access: 19 July 2016.

Wang, J., Rich, P., and Price, K.: Temporal responses of NDVI to precipitation and temperature in the central Great Plains, USA, Int. J. Remote Sens., 24, 2345-2364, https://doi.org/10.1080/01431160210154812, 2003.

Wardlow, B. D., Egbert, S. L., and Kastens, J. H.: Analysis of timeseries MODIS $250 \mathrm{~m}$ vegetation index data for crop classification in the US Central Great Plains, Remote Sens. Environ., 108, 290 310, https://doi.org/10.1016/j.rse.2006.11.021, 2007.

Way, D. A.: Tree phenology responses to warming: spring forward, fall back?, Tree Physiol., 31, 469-471, https://doi.org/10.1093/treephys/tpr044, 2011.

Wheeler, J., Hoch, G., Cortés, A. J., Sedlacek, J., Wipf, S., and Rixen, C.: Increased spring freezing vulnerability for alpine shrubs under early snowmelt, Oecologia, 175, 219-229, https://doi.org/10.1007/s00442-013-2872-8, 2014.

Wreford, A. and Adger, N.: Adaptation in agriculture: historic effects of heat waves and droughts on UK agriculture, Int. J. Agr. Sustain., 8, 278-289, https://doi.org/10.3763/ijas.2010.0482, 2010.

Zscheischler, J., Orth, R., and Seneviratne, S. I.: A submonthly database for detecting changes in vegetationatmosphere coupling, Geophys. Res. Lett., 42, 9816-9824, https://doi.org/10.1002/2015GL066563, 2015. 